\title{
Strong expression of methylthioadenosine phosphorylase (MTAP) in human colon carcinoma cells is regulated by TCF1/[beta]-catenin
}

\author{
Frauke Bataille ${ }^{1}$, Gerhard Rogler ${ }^{2}$, Katharina Modes ${ }^{1}$, Ina Poser ${ }^{1}$, Marion Schuierer ${ }^{1}$, \\ Wolfgang Dietmaier ${ }^{1}$, Petra Ruemmele ${ }^{1}$, Marcus Mühlbauer ${ }^{2}$, Susanne Wallner ${ }^{1}$, \\ Claus Hellerbrand ${ }^{2}$ and Anja-Katrin Bosserhoff ${ }^{1}$ \\ ${ }^{1}$ Institute of Pathology and ${ }^{2}$ Department of Internal Medicine I, University of Regensburg Medical School, \\ Regensburg, Germany
}

\begin{abstract}
Methylthioadenosine phosphorylase (MTAP) is known as a ubiquitously expressed house keeping gene important in biochemical salvage processes. The MTAP gene is localized on the human chromosomal region 9p21, a region often deleted in cancer. Recently, several groups including our own have shown that MTAP serves as a tumour suppressor gene. The aim of this study was to analyse the role of MTAP in colon carcinoma and normal colon epithelium and the regulation of gene expression. To examine MTAP RNA and protein expression, we screened six colon carcinoma cell lines and human primary colon epithelial cells by RT-PCR and immunoblotting. MTAP expression was confirmed in vivo by immunohistochemical staining of normal colon tissue compared to adenoma and colon carcinoma. Interestingly, we found strong MTAP mRNA and protein expression by colon carcinoma cell lines but no expression by colonic epithelial cells. To analyse the regulation of MTAP expression, promoter studies were performed and revealed control of MTAP expression by LEF/TCF/ $\beta$ catenin. Furthermore, we demonstrated a significant correlation between MTAP protein expression and tumour progression as the intensity of MTAP protein staining increased from normal tissue to carcinoma. In addition, the recently postulated association between MTAP activity and interferon (IFN) sensitivity was confirmed in colon epithelial cells showing only little response to IFN-gamma, in contrast to the carcinoma cell lines. In summary, these data indicate for the first time that MTAP is not expressed in normal human colonic epithelium but is strongly upregulated in colon carcinoma. This finding may be of clinical significance concerning the homeostasis of normal colon epithelium and potential treatment of colon carcinoma.
\end{abstract}

Laboratory Investigation (2005) 85, 124-136, advance online publication, 18 October 2004; doi:10.1038/labinvest.3700192

Keywords: MTAP; colon carcinoma; colonic epithelial cells; interferon

Methylthioadenosine phosphorylase (MTAP, EC 24. 2.28) plays a major role in polyamine metabolism and is important for the salvage of both adenine and methionine. MTAP catalyses the phosphorylation of methylthioadenosine (MTA), a by-product of the synthesis of polyamines, which acts as a potent inhibitor of polyamine aminopropyltransferase and methyltransferases. MTAP has been shown previously to be expressed abundantly in normal cells and tissues. ${ }^{1}$

Correspondence: Professor A-K Bosserhoff, $\mathrm{PhD}$, Institute of Pathology, University of Regensburg, Franz-Josef-Strauss-Allee 11, D-93053 Regensburg, Germany.

E-mail: anja.bosserhoff@klinik.uni-regensburg.de

Received 25 May 2004; revised and accepted 8 September 2004; published online 18 Ocober 2004
In contrast, many malignant cells lack MTAP activity, ${ }^{2-5}$ and cultured MTAP-deficient cells secrete MTA instead of metabolising it. ${ }^{6}$ The reason for the frequent loss of MTAP activity became evident after determining the chromosomal location of MTAP. Starting from the centromeric end, the gene order on human chromosome 9p21 was mapped as p15-p16-MTAP-interferon(IFN)-alpha-IFNbeta. ${ }^{1}$ In this region, many tumours reveal selective deletions. Recently, MTAP gene deletions were described in endometrial cancer, osteosarcoma and in haematological neoplasias like lymphoblastic leukaemia or non-Hodgkin's lymphomas. ${ }^{2-5}$

In addition to its role in polyamine metabolism, MTAP expression has recently been shown to have significant impact on signal transducer and activator of transcription (STAT) 1 activity. $^{7}$ STAT1 is 
essential for IFN-gamma signalling pathways ${ }^{8}$ and plays an important role in the pathophysiology of colonic inflammation. ${ }^{9}$ IFN-gamma regulates many epithelial functions including permeability and expression of MHC $\mathrm{II}^{10,11}$ and is involved in the regulation of apoptosis in colon carcinoma. ${ }^{12}$

In this study, we investigated the MTAP expression in colon carcinoma cell lines in comparison to primary colonic epithelial cells, and analysed MTAP expression in vivo in colon carcinoma and normal colon by immunohistochemistry. Interestingly, we found that MTAP expression in healthy as well as tumorous colonic epithelium differs when compared to other tissues.

\section{Materials and methods}

\section{Isolation of Colonic Epithelial Cells}

Colonic epithelial cells (CEC) were isolated as previously described. ${ }^{13,14}$ Briefly, intestinal mucosa was stripped from the submucosa within $30 \mathrm{~min}$ after bowel resection and rinsed several times with PBS at room temperature. The mucus was removed by rotating the resection two times in $1 \mathrm{mM}$ dithiothreitol (DTT) (Sigma, Deisenhofen, Germany) for $15 \mathrm{~min}$ at $37^{\circ} \mathrm{C}$. After washing with PBS to remove DTT, the mucosa was rotated in $2 \mathrm{mM}$ EDTA in HANKS balanced salt solution without calcium and magnesium (PAA, Linz, Austria) for $10 \mathrm{~min}$ at $37^{\circ} \mathrm{C}$. The resulting supernatant, containing debris and mainly villus cells, was discarded. The remaining mucosa was vortexed in PBS and the supernatant, containing complete crypts and some single cells, was collected into a $15 \mathrm{ml}$ tube. Vortexing was repeated until the supernatant was almost clear. To separate crypts from single cells (partially nonepithelial cells), the suspension was allowed to settle for 3 to $5 \mathrm{~min}$. All these steps were carried out at room temperature. The sedimented crypts were collected, washed with PBS and cell viability was assessed by $0.1 \%$ trypan blue exclusion and flow cytometry.

\section{Cell Lines and Culture Conditions}

The colon carcinoma cell lines CaCo-2 (ATCC HTB37), HT29 (ATCC HTB-38), SW48 (ATCC CCL-231), SW480 (ATCC CCL-228), HCT116 (ATCC CCL-247) and LoVo (ATCC CCL-229) were used for in vitro experiments. The cell line HT29M3 was chosen as a highly differentiated colon carcinoma cell line. ${ }^{15-18}$ Furthermore, the melanoma cell line Mel $\mathrm{Im}^{19}$ and the mammary carcinoma cell line MCF-7 (ATCC HTB-22) were analysed. For tissue culture, the cells were maintained in DMEM supplemented with penicillin $(400 \mathrm{U} / \mathrm{ml})$, streptomycin $(50 \mu \mathrm{g} / \mathrm{ml})$, L-glutamine $(300 \mu \mathrm{g} / \mathrm{ml})$ and $10 \%$ fetal calf serum (FCS; Sigma, Deisenhofen, Germany) and splitted 1:5 every 3 days. Cells were detached for subcultivation or assays with $0.05 \%$ trypsin/0.04\% EDTA in PBS.

\section{Microsatellite Analysis}

Genomic DNA specimens were prepared from cell lines using the QIAamp blood kit following the manufacturer's instructions (Qiagen, Hilden, Germany). Genomic DNA samples (50-100 ng) were used for PCR amplification in a final volume of $25 \mu \mathrm{l}$ containing $0.2 \mathrm{mmol} / \mathrm{l}$ dNTP, $0.2 \mu \mathrm{mol} / \mathrm{l}$ primers, $1.5 \mathrm{mmol} / \mathrm{l} \mathrm{MgCl}_{2}$, and $0.5 \mathrm{U}$ Taq polymerase (Roche Diagnostics $\mathrm{GmbH}$, Mannheim, Germany). The reaction mixture was denatured for $3 \mathrm{~min}$ at $94^{\circ} \mathrm{C}$, and 35 cycles $\left(1 \mathrm{~min}\right.$ at $94^{\circ} \mathrm{C}, 1 \mathrm{~min}$ at specific annealing temperature and $1 \mathrm{~min}$ at $72^{\circ} \mathrm{C}$ ) of PCR amplification were performed. This step was followed by a final extension step at $72^{\circ} \mathrm{C}$ for $8 \mathrm{~min}$. PCR conditions were optimised by gradient PCR and carried out in an MJ Research Thermocycler (PTC200). A volume of $1 \mu \mathrm{l}$ of NED-, Fam- or Hex-labelled PCR product was mixed with $12 \mu$ l formamide and $0.7 \mu \mathrm{l}$ GeneScan Rox-400 size standard (Applied Biosystems, Warrington, UK). The samples were denatured for $2 \mathrm{~min}$ at $95^{\circ} \mathrm{C}$ and subsequently analysed by capillary electrophoresis on a ABI Prism 3100 Genetic Analyzer using GeneScan Analysis software 3.1 (Applied Biosystems, Foster City, CA, USA). Primer sequences of D9S304 (9p21) and D9S775 (9p23-p22) were 5'-GTGCACCTCTA CACCCAGAC-3' (D9S304-f), 5'-TGT GCC CAC ACA CAT CTA TC-3' (D9S304-r), 5'-AAA GTA GCC ATC CGT GTG T-3' (D9S775-f), 5-GCT TTC TTT GAT GGT TTA CAG-3' (D9S775-r). Primer sequences of control markers BAT25, BAT26, D5S346, D2S123 and Mfd15 are given in Dietmaier et al. ${ }^{20}$ These were used to ensure DNA quality.

\section{Stable Transfection of Melanoma Cells with MTAP Expression Plasmid}

A panel of HT29M3 cell clones showing re-expression of MTAP were established by stable transfection with MTAP-sense expression plasmid (MTAP full length cDNA cloned into pCDNA3 (Invitrogen NV Leek, Holland). Controls received pcDNA3 alone. Transfections were performed using the lipofectamine plus method (Invitrogen). At 1 day after transfection, cells were placed into selection medium containing $50 \mu \mathrm{g} / \mathrm{ml}$ G418 (Sigma). After 25 days of selection, individual G418-resistant colonies were subcloned. The amount of MTAP expression in these clones was determined by RT-PCR and Western blot analysis.

\section{Proliferation Assay}

Proliferation of the colon carcinoma cell lines was measured as described previously. ${ }^{19}$ IFN-gamma (Sigma) concentrations of 100, 1000 and $10000 \mathrm{U} / \mathrm{ml}$ were used. Results were expressed as mean \pm s.d. (range) or per cent. Correlation between parameters 
was calculated with the Student's $t$-test. A $P$-value $<0.05$ was considered statistically significant.

\section{RNA Isolation, Reverse Transcription and PCR}

For RT-PCR, total cellular RNA was isolated from cultured cells or tissue using the RNeasy kit (Qiagen). The integrity of the RNA preparations was controlled on an 1\% agarose/formaldehyde gel and, subsequently, cDNAs were generated by reverse transcriptase reaction. The RT-reaction was performed in $20 \mu \mathrm{l}$ reaction volume containing $2 \mu \mathrm{g}$ of total cellular RNA, $4 \mu \mathrm{l}$ of $5 \times$ first strand buffer (Gibco), $2 \mu \mathrm{l}$ of $0.1 \mathrm{M}$ DTT, $1 \mu \mathrm{l}$ of $\mathrm{dN}_{6}$-primer (10 mM), $1 \mu \mathrm{l}$ of dNTPs $(10 \mathrm{mM})$ and DEPC-water. The reaction mix was incubated for $10 \mathrm{~min}$ at $70^{\circ} \mathrm{C}$. Then $1 \mu \mathrm{l}$ of Superscript II reverse transcriptase (Gibco) was added and RNAs were transcribed for $1 \mathrm{~h}$ at $37^{\circ} \mathrm{C}$. Subsequently, reverse transcriptase was inactivated at $70^{\circ} \mathrm{C}$ for $10 \mathrm{~min}$ and RNA was degraded by digestion with $1 \mu \mathrm{l}$ RNase A $(10 \mathrm{mg} / \mathrm{ml})$ at $37^{\circ} \mathrm{C}$ for $30 \mathrm{~min}$. cDNAs were controlled by PCR amplification of $\beta$-actin. LEF1, TCF1, p15 and p16 were amplified using standard PCR programs and the following primers: LEF1 for CAA CTG GCA TCC CTC ATC; LEF1rev for GCA ACG ACA TTC GCT CTC; TCF1 for AAG GAG ATG AGA GCC AAG GTC; TCF1rev for GGT ATG AGG GTG AGT CCT GG; p15 for AAA GCC CGG AGC TAA CGA CCG GCC; p15rev for CCG AAA CGG TTG ACT CCG TTG GGA TC; 16 for GCG GAA GGT CCC TCA GAC ATC CCC; and p16rev for CTC GCA AGA AAT GCC CAC ATG AAT GTG C.

\section{Analysis of MTAP mRNA Expression by Quantitative PCR}

Quantitative real-time PCR was performed on a Lightcycler (Roche, Mannheim, Germany). A volume of $2 \mu \mathrm{l}$ cDNA template, $2 \mu \mathrm{l} 25 \mathrm{mM} \mathrm{MgCl}_{2}$, $0.5 \mu \mathrm{M}$ of forward and reverse primers (MTAP for2, MTAP rev2 ${ }^{21}$ ), and $2 \mu \mathrm{l}$ of SybrGreen LightCycler Mix in a total of $20 \mu \mathrm{l}$ were applied to the following PCR program: $30 \mathrm{~s} 95^{\circ} \mathrm{C}$ (initial denaturation); $20^{\circ} \mathrm{C} / \mathrm{s}$ temperature transition rate up to $95^{\circ} \mathrm{C}$ for $15 \mathrm{~s}, 3 \mathrm{~s}$ $58^{\circ} \mathrm{C}, 5 \mathrm{~s} 72^{\circ} \mathrm{C}, 81^{\circ} \mathrm{C}$ acquisition mode single, repeated for 40 times (amplification). The PCR reaction was evaluated by melting curve analysis following the manufacturer's instructions and checking the PCR products on $1.8 \%$ agarose gels. Each measurement was repeated three times.

\section{Reporter Gene Assays}

A $1420 \mathrm{bp}$ fragment of the promoter region of the MTAP gene $\left(5^{\prime}\right.$ of the start of exon 1$)$ was amplified by PCR and subcloned into pGL3-basic (Promega). The activity of the construct was measured in each of the colon carcinoma cell lines. For transient transfections, $2 \times 10^{5}$ cells per well were seeded into six-well plates and transfected with $0.5 \mu \mathrm{g}$ of MTAP promoter reporter plasmids using the lipofectamine plus method (Gibco) according to the manufacturer's instructions. For cotransfection, $0.2 \mu \mathrm{g} /$ well of expression plasmids for TCF1, TCF4, LEF1 and $\beta$-catenin were used, respectively. At $48 \mathrm{~h}$ after transfection, the cells were lysed and the luciferase activity in the lysate was measured. To normalize transfection efficiency, $0.2 \mu \mathrm{g}$ of a pRL-TK plasmid (Promega, Mannheim, Germany) was cotransfected and renilla luciferase activity was measured by a luminometric assay (Promega). All transfection experiments were repeated at least three times.

\section{EMSA}

A double-stranded oligonucleotide corresponding to the TCF/LEF binding site in the MTAP promoter (5'-CCTATTCCTCAAAGGAGCACCCG-3') was phospholabelled and used for gel mobility shift assays. Nuclear extracts of the colon carcinoma cell line HT29 (8 $\mu \mathrm{g}$ /lane) were used for EMSA experiments. ${ }^{22}$ Competition was performed using an unlabelled oligonucleotide of the TCF/LEF binding site of the MTAP promoter or a consensus LEF/TCF binding site. For supershifting, nuclear extracts were incubated with different antibodies (antiTCF1 (2.5 $\mu \mathrm{g} / \mathrm{lane}$; Santa Cruz) and anti- $\beta$-catenin (1 $\mu \mathrm{g} /$ lane; BD Bioscience)) and gel shifts were performed as described previously. ${ }^{22}$

\section{Protein Analysis In Vitro (Western-Blotting)}

For protein isolation, $2 \times 10^{6}$ cells were washed in $1 \times$ PBS and lysed in $200 \mu$ l RIPA-buffer (Roche). The protein concentration was determined using the BCA protein assay reagent (Pierce, USA). Balanced amounts of cell proteins $(20 \mu \mathrm{g})$ were denatured at $94^{\circ} \mathrm{C}$ for $10 \mathrm{~min}$ after addition of Roti-load-buffer (Roth, Karlsruhe, Germany) and subsequently separated on NuPage-SDS-gels (Invitrogen, Groningen, The Netherlands). After transferring the proteins onto PVDF-membranes (BioRad, Richmond, USA), the membranes were blocked in 3\% BSA/PBS for $1 \mathrm{~h}$ and incubated with a 1:1.000 dilution of the primary polyclonal chicken anti-MTAP antibody (generous gift from Dr D Carson, University of California) overnight at $4^{\circ} \mathrm{C}$. A 1:20.000 dilution of rabbit antiIgY-AP (Sigma) was used as secondary antibody. Staining was performed using BCIP/NBT-tablets (Sigma).

\section{Immunohistochemistry}

Tissue samples from eight patients with colon adenoma $(4 \times$ low-grade dysplasia, $4 \times$ high-grade dysplasia) and six patients with colon carcinoma were obtained. Tissue specimens were fixed in $4 \%$ 
buffered formalin for $24 \mathrm{~h}$ and embedded in paraffin. Histological sections were stained with haematoxylin and eosin; tumours were graded and classified according to the TNM Classification of Malignant Tumours. ${ }^{23}$ This study was approved by the Ethic's Committee of the University of Regensburg. An informed consent was signed by each patient.

For MTAP protein expression analysis, paraffinembedded paired normal and tumour tissue samples from patients with colon adenoma and carcinoma were screened by immunohistochemistry. The tissues were deparaffinated, rehydrated and subsequently incubated with the primary polyclonal chicken anti-MTAP antibody (1:1.500, generous gift from Dr D Carson, University of California) overnight at $4^{\circ} \mathrm{C}$. The secondary antibody (biotinlabelled anti-chicken, 1:1.000, Immuno Research, USA) was incubated for $30 \mathrm{~min}$ at room temperature, followed by incubation with streptavidin-POD (DAKO) for $30 \mathrm{~min}$. Antibody binding was visualised using AEC-solution (DAKO). Finally, the tissues were counterstained by hemalaun.

\section{Results}

\section{Expression of MTAP in Colon Carcinoma Cell Lines and Primary CEC}

Since it has been shown previously that the expression of MTAP is reduced or totally lost in several tumours compared to the normal tissue, ${ }^{2-5,21}$ we analysed MTAP mRNA expression in six colon carcinoma cell lines in comparison to primary human CEC using quantitative PCR. Primary human melanocytes and total human liver tissue served as control, since both had been shown previously to express high levels of MTAP. ${ }^{21}$

In contrast to several other tumours reported, strong expression of MTAP mRNA was found in five out of six analysed colon carcinoma cell lines comparable to the expression levels in primary human melanocytes and total human liver tissue, respectively (Figure 1a). Only the colon carcinoma cell line SW480 showed relatively weak expression of MTAP. Interestingly, CEC derived from normal colon revealed only weak MTAP mRNA expression. Here, the expression levels were comparable to melanoma (Figure 1a) or other extraintestinal tumour cells (data not shown).

In addition to the colon carcinoma cell lines HT29, SW48, HCT116, CaCo-2, SW480 and LoVo, and primary CEC, we analysed the cell line HT29M3. This cell line, derived from HT29, is known to be highly differentiated. ${ }^{15-18}$ Similar to CEC, only weak MTAP expression was detected in HT29M3 cells in comparison to undifferentiated HT29 or other colon carcinoma cell lines (Figure 1b).

In order to investigate if allelic losses at 9p21, where the MTAP gene is located, may affect MTAP expression, we performed microsatellite analysis using the D9S304 marker (Figure 1c). We found a biallelic pattern in all but one cell line (SW480). Thus, both alleles at 9p21 are present in each cell line with strong MTAP expression. The one cell line with weak expression (SW480) has only one allele. Either this marker is not informative in this cell line or loss of heterozygosity could be associated with a lower MTAP expression.

In addition to microsatellite analysis, we successfully amplified p15 and p16 by RT-PCR to verify an intact genomic region since both genes are located next to the MTAP gene on 9p21 ${ }^{1}$ (Figure 1d).

\section{MTAP Protein Expression in Colon Carcinoma Cell Lines}

To verify the strong MTAP expression in the colon cancer cell lines on the protein level, we screened these cells and HT29M3 cells for MTAP expression by Western blotting using an anti-MTAP-antibody (Figure 2). The results of the immunoblotting correlated with the MTAP mRNA expression. Consistent with the mRNA expression levels, MTAP protein was detected in HT29, SW48, HCT116, CaCo-2, SW480 and LoVo. In five out of six cell lines expression levels were similar to MTAP levels in total liver protein extracts, which served again as positive control. In contrast to these findings but in accordance with the mRNA expression, in SW480 only weak and in HT29M3 almost no MTAP protein expression was found.

\section{Analysis of MTAP Protein Expression In Vivo}

Next, we wanted to verify in vivo the finding that colon carcinoma cells express high levels of MTAP in contrast to nontumorous CEC and to tumour cells from other tissues. In situ MTAP expression was examined in colon carcinomas and in nontumorous colonic tissue samples, respectively, using immunohistochemistry.

In accordance with the in vitro findings, almost no staining was found in the colon epithelium (Figure 3a). Only some cells at the top of the crypts showed MTAP expression (black arrow). In contrast, the immunoreactivity and the percentage of MTAPpositive cells were significantly increased in colon carcinoma (Figure 3b). Immunostaining of normal skin was performed as control (Figure 3c). Consistent with previous studies, ${ }^{21}$ keratinocytes, fibroblasts and endothelial cells showed strong immunosignals, supporting the theory that MTAP is an ubiquitous house keeping gene expressed by most normal cells, but not in the colonic epithelium.

Analysing the adenoma-carcinoma sequence of colon carcinogenesis, we found a gradual increase from no staining in normal epithelium, weak to moderate staining in adenoma with low-grade dysplasia and strong expression in high-grade dysplasia and colon carcinoma (Figure 4a-d). 

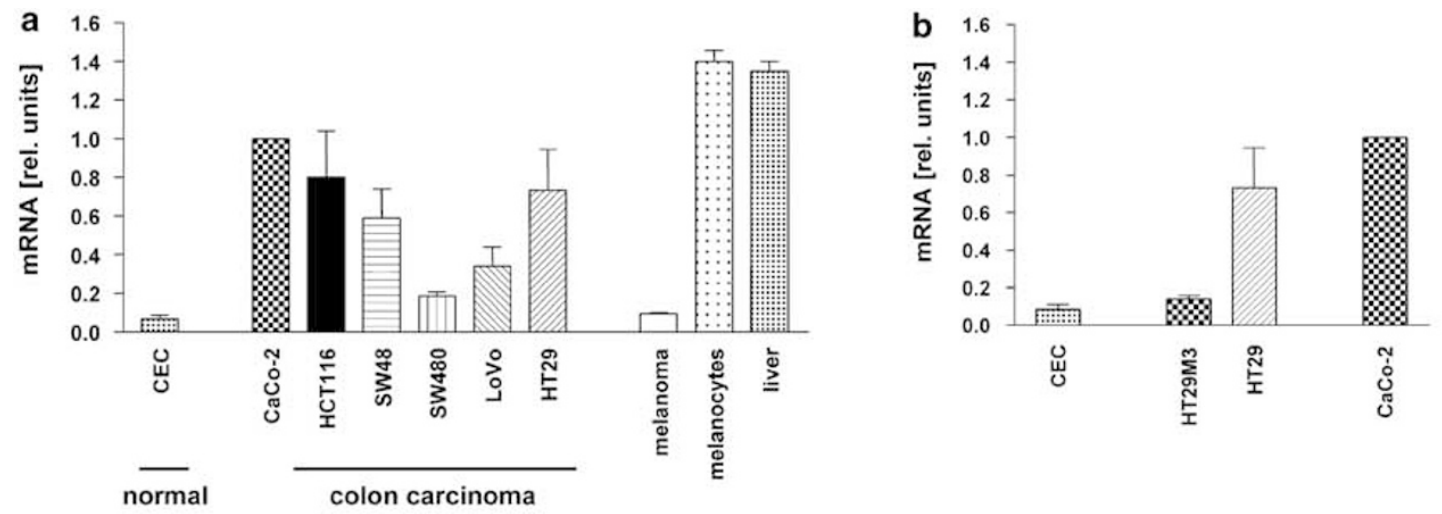

C

Fragment length [bp]

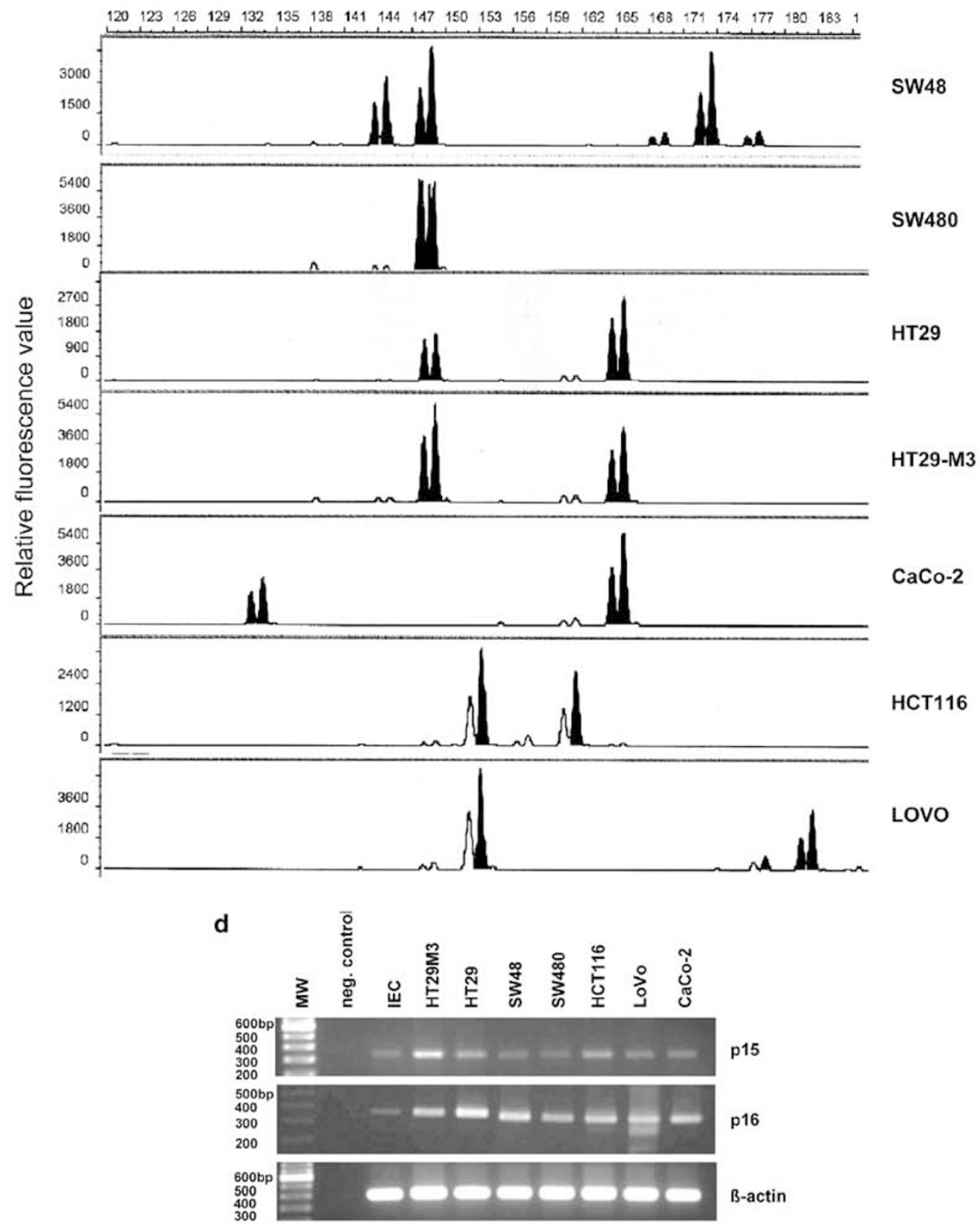




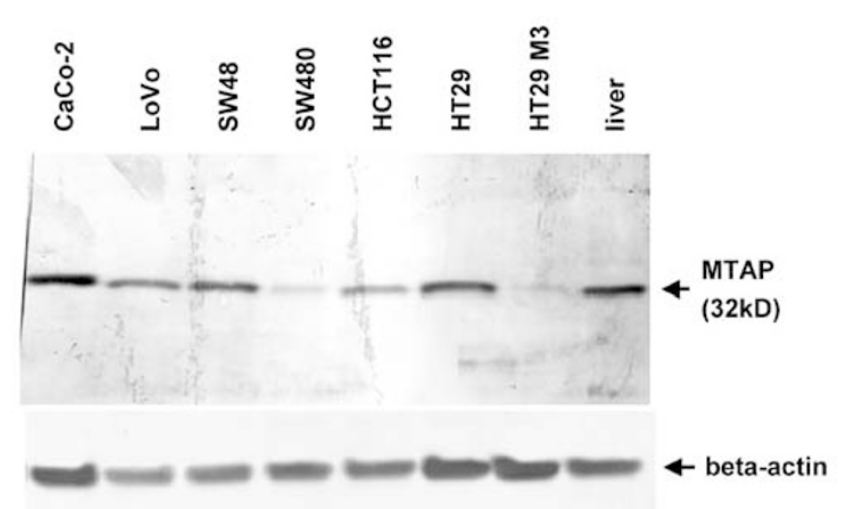

Figure 2 Western blot analysis of MTAP protein expression in colon carcinoma cell lines and HT29M3 cells. In five out of six colon carcinoma cell lines the expression of MTAP protein was almost as strong as in healthy liver that was used as a positive control with known high MTAP protein expression. In contrast, HT29M3 cells showed only minimal MTAP expression. Beta-actin staining was performed to ensure equal loading.

\section{Regulation of MTAP Expression}

To further analyse the regulation of MTAP gene expression, we performed reporter assays utilizing an expression vector under the control of an $1420 \mathrm{bp}$ fragment of the MTAP promoter. The empty vector pGL3-basic served as a negative control. In colon carcinoma cell lines, high transcriptional activity levels were detected (Figure 5a) that correlated with the mRNA and protein expression levels (Figures 1a and 2). In contrast to the carcinoma cell lines but in accordance to mRNA and protein expression data, only minimal transcriptional activity was detected in HT29M3 cells.

These data indicate that the high expression of MTAP in colon carcinoma cell lines in contrast to normal colonic epithelium is regulated on the transcriptional level. To determine transcription factors involved in this regulation, we carefully analysed the promoter region and identified consensus sites for binding of TCF/LEF, Oct, Sp1, AP1, NF-AT, CEBP, GATA and NFкB. The DNA sequence (CTCAAAGG) similar to LEF/TCF binding site (A/T A/T CAA A/T GG) at position -1302 (with + 1 defined as the start of exon 1) was most promising since previously TCF/LEF have been shown to be important in colon carcinoma development. Consequently, expression of LEF1 and TCF1 was verified by RT-PCR and reporter gene assays of the MTAP promoter and cotransfection of LEF1, TCF1, TCF4 and $\beta$-catenin expression plasmids were performed. Strong induction of MTAP promoter activity was seen after cotransfection of TCF1 and $\beta$-catenin (Figure 5b). Cotransfection of LEF1 resulted in weak activation of the MTAP promoter and TCF4 did not reveal any effect. In gel shift assays, specific binding of the identified factors to the defined promoter region was analysed. Defined bands were detectable using HT29 nuclear extracts (Figure 5c). Specific competition was possible using either the DNA region derived from the MTAP promoter or a consensus TCF/LEF binding site. Furthermore, supershift assays using an anti-TCF1 and an anti- $\beta$ catenin antibody were performed, demonstrating specific TCF1/ $\beta$-catenin binding to the promoter region. The anti-TCF1 antibody suppressed binding of TCF 1 to DNA. The anti- $\beta$-catenin antibody bound to the complex and induced a supershift. Next, expression of LEF-1 and TCF-1 in the colon carcinoma cell lines was determined by RT-PCR (Figure 5d). Only in LoVo, HCT116 and SW480 LEF-1 were found to be strongly expressed. In contrast, TCF-1 was detectable in all colon carcinoma cell lines while no or only weak expression was detected in CEC and HT29M3, respectively. TCF4 was detected in all colon carcinoma cell lines and in CEC (data not shown).

In accordance with regulation of MTAP via TCF/ $\mathrm{LEF} / \beta$-catenin, we found a correlation between nuclear/cytoplasmatic $\beta$-catenin and MTAP expression in situ by immunohistochemistry (Figure 6a and b). In healthy colon epithelium (Figure 6a), the cells in the top of the crypts expressing MTAP lost membranous $\beta$-catenin staining. A similar association was found in colon carcinoma (Figure 6b) where strong nuclear staining of $\beta$-catenin was correlated to increasing amounts of MTAP.

To clarify if regulation of MTAP expression by TCF-1/ $\beta$-catenin is colon-specific, we also investigated melanoma (Mel Im) and mammary carcinoma (MCF-7) cell lines. As published previously, MTAP expression is strongly downregulated in melanoma cells due to promoter hypermethylation. ${ }^{21}$ However, in reporter gene assays, we found strong activity of the MTAP promoter in melanoma cells since DNA amplified in Escherichia coli is not subject to methylation. ${ }^{21}$ The effect of LEF-1, TCF-4, TCF-1 and $\beta$-catenin on transcriptional activity of the MTAP promoter was analysed. Interestingly, in both

Figure 1 MTAP expression in colon carcinoma cell lines compared to primary human CEC and the highly differentiated cell line HT29M3. (a) The amount of MTAP mRNA expression was carefully quantified by real-time PCR. All colon carcinoma cell lines showed a strong expression of MTAP compared to human primary hepatocytes and melanocytes that served as control. Isolated primary human CEC of six different donors showed almost no MTAP expression comparable to the weak expression in melanoma cells. ${ }^{21}$ (b) By real-time PCR it was shown that the amount of MTAP mRNA expression in HT29M3 resembles the weak expression in primary human CEC. Data shown represents the mean of three experiment ( \pm s.d.). MTAP expression in CaCo-2 was set as 1 . (c) By microsatellite analysis of 9p21 a biallelic amplification in all but one colorectal cancer cell line (SW480) was shown. (d) By RT-PCR amplification expression of p15 and p16 in the colon carcinoma cell lines was analysed. All colon carcinoma cell lines showed expression of p15 and p16. 
130
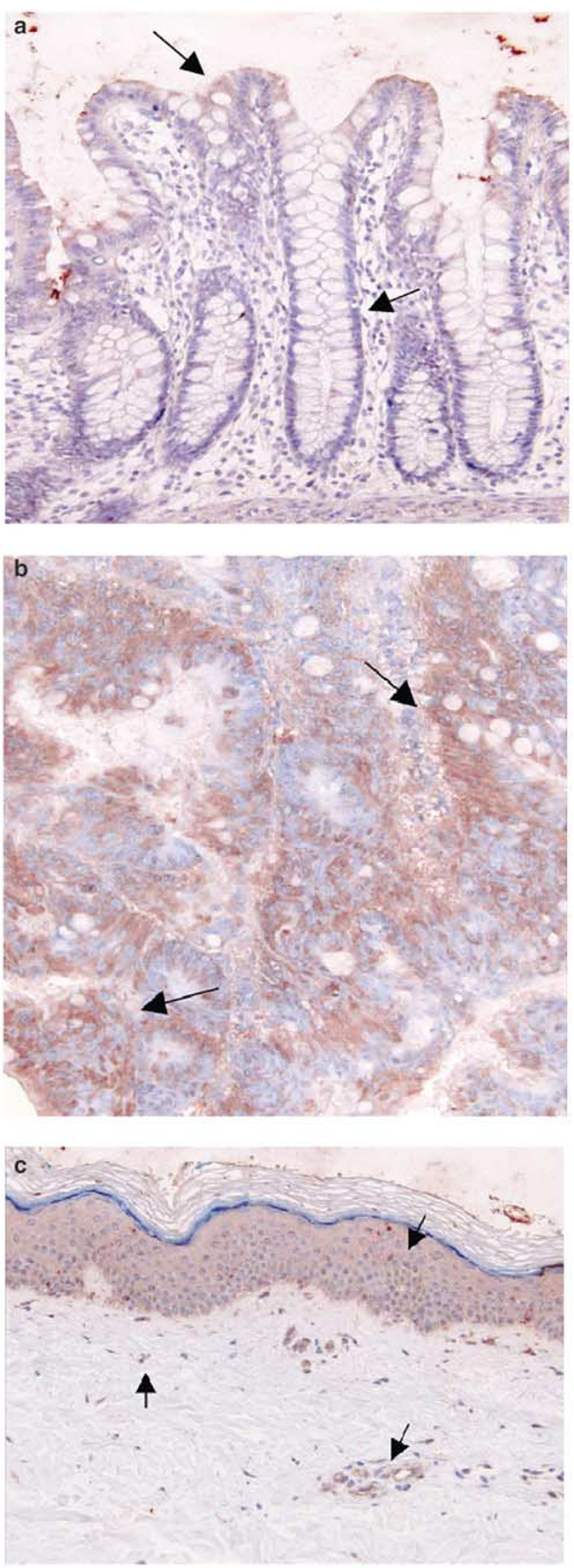

cell types no induction of MTAP promoter activity by cotransfection of LEF-1, TCF-1 or TCF-4 was found (data not shown).

\section{Functional Relevance of MTAP Expression}

Since it has been shown recently that MTAP expression has a significant impact on STAT activity $^{7}$ and STAT is essential for IFN-gamma signalling pathways,${ }^{8}$ we analysed the antiproliferative effect of IFN-gamma on the colon carcinoma cell lines HT29, CaCo-2 (both showing strong expression of MTAP), SW480 (showing weak expression of MTAP) and the more differentiated colon cell line HT29M3 cells (showing almost no expression of MTAP) (Figure 7). Interestingly, cells with the highest MTAP expression levels were most sensitive to the antiproliferative IFN-gamma effects. At concentrations of $100 \mathrm{U}$, approximately $50 \%$ growth inhibition was observed in HT29 cells and CaCo-2 cells. In contrast, SW480 and HT29M3 cells were not responsive to $100 \mathrm{U}$ of IFN-gamma. In these cells, 100-fold higher IFN-gamma concentrations were necessary to induce antiproliferative effects.

To confirm these data, we induced expression of MTAP by stable transfection of the cell line HT29M3 with an MTAP expression construct. Overexpression of MTAP in the cell clones (MTAP1, 2 and 3) compared to mock-transfected cell clones (HT29M3 mock1, 2) was demonstrated by quantitative RT-PCR (Figure 8a, upper panel) and Western blotting (Figure 8a, lower panel). Proliferation assays revealed no changes in proliferation comparing the MTAP-expressing cell clones to the mock control (doubling times: mock1 and 2: $4.6 \pm 0.75$ days; MTAP1, 2 and 3: $6.4 \pm 0.65$ days; not significant). However, the MTAP-expressing HT29M3 cell clones revealed significant stronger response to IFN-gamma treatment (Figure 8b). Whereas treatment of mocktransfected cells did not result in significant antiproliferative effects, significant inhibition of proliferation of the MTAP-expressing cell clones was found applying $1000 \mathrm{U} / \mathrm{ml}$ IFN and higher concentrations.

Furthermore, as proliferation per se was not changed comparing MTAP-expressing and nonexpressing HT29M3 cell clones, we additionally analysed their invasive potential in Boyden Chamber assays. Re-expression of MTAP in the HT29M3 cell line led to significant induction of invasion by the cell clones compared to the wild-type HT29M3

Figure 3 Immunostaining of MTAP in normal colon epithelium and colon carcinoma. (a) Negative or weak staining pattern was found in colon epithelium (arrows, $\times 100$ ). (b) Strong cytoplasmatic staining was seen in colon carcinoma (arrows, $\times 200$ ). (c) Strong cytoplasmatic staining was detected in all cell types in normal skin (keratinocytes, fibroblasts, endothelial cells (arrows), $\times 100$ ). Immunosignals were developed in red (AEC). Slides were counterstained with hemalaun. 

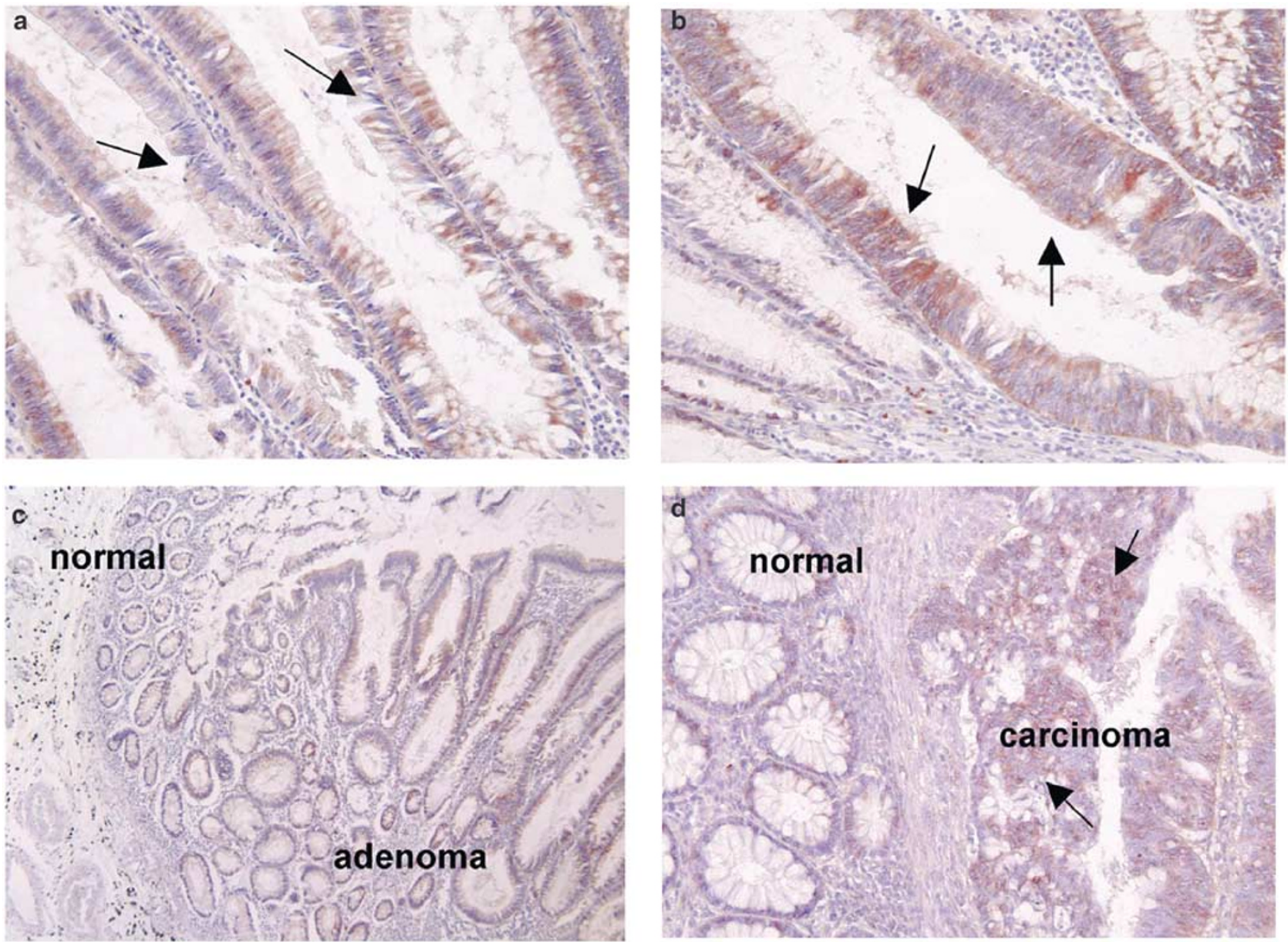

Figure 4 Immunostaining of MTAP in colon adenoma and carcinoma. (a) Colon adenoma with low-grade dysplasia. Only moderate cytoplasmatic staining was detectable (arrows, $\times 200$ ). (b) Colon adenoma with high-grade dysplasia. Strong cytoplasmatic staining was found (arrow, $\times 200$ ). (c) and (d) Colon carcinoma with residual colon adenoma and normal colon epithelium at the margins. (c) A graduation from no staining of the normal colon epithelium (normal) to strong staining of the colon adenoma (adenoma) (high-grade dysplasia) $(\times 50)$ and (d) in the colon carcinoma (black arrows, (carcinoma)) with normal colon epithelium left half of the figure (normal). $(\times 100)$

cells $(P<0.001)$. No difference between the wildtype cells and the mock-transfected controls was found. Interestingly, the invasive potential of the MTAP-expressing HT29M3 cell clones was comparable to HT29 colon carcinoma cells (Figure 8c).

\section{Discussion}

The aim of this study was to investigate MTAP expression in colon carcinoma in comparison to normal colonic epithelium, and to gain insight into the regulation and functional role of MTAP expression in colon carcinoma.

Surprisingly, while MTAP was considered as a ubiquitous 'house keeping' gene, ${ }^{1}$ we found human CEC as the first nontumorous cells almost completely lacking MTAP expression. In vitro and in vivo data on RNA and protein level clearly demonstrated the lack of MTAP expression in primary colon epithelial cells and a highly differentiated subclone of HT29 cells (HT29M3), respectively.
Furthermore, in contrast to published data on other kinds of cancer where MTAP expression is often lost completely, ${ }^{2-5}$ we found a strong upregulation of MTAP expression in colon carcinoma. Expression levels were comparable to normal tissue such as liver. Promoter studies indicated that the high MTAP expression in colon carcinoma is regulated at the transcriptional level. Interestingly, promoter analysis revealed that the regulation of MTAP expression is controlled by TCF1/ $\beta$-catenin. Several genes important for migration and proliferation in normal colonic epithelium at the top of the crypts and as well as in colon carcinoma are known to be controlled by the LEF/TCF family of transcription factors. ${ }^{24-32}$ Here, we could identify MTAP as one further gene upregulated during epithelialmesenchymal transition. Interestingly, in other cell types tested no induction of MTAP promoter activity by cotransfection of LEF-1, TCF-1 or TCF-4 was found. These findings led us to the hypothesis that MTAP regulation is not ubiquitous but seems to be colon specific. 

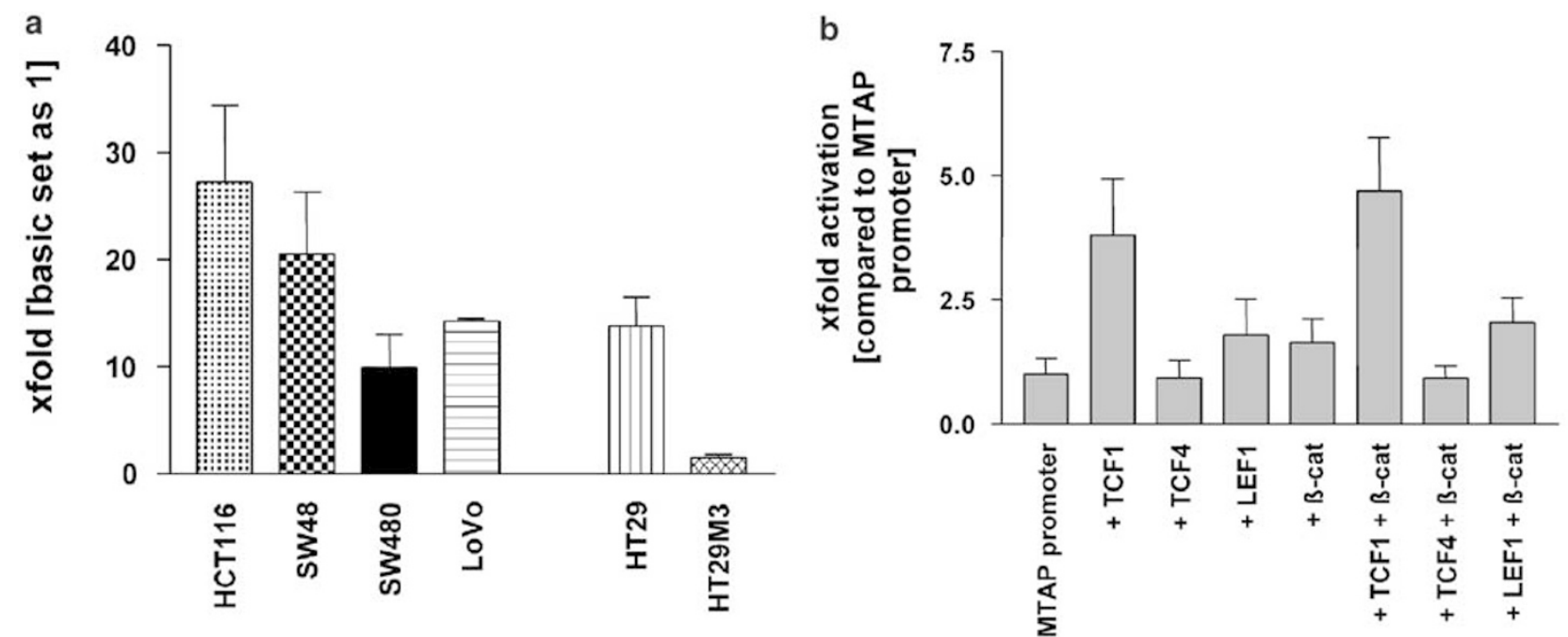

C

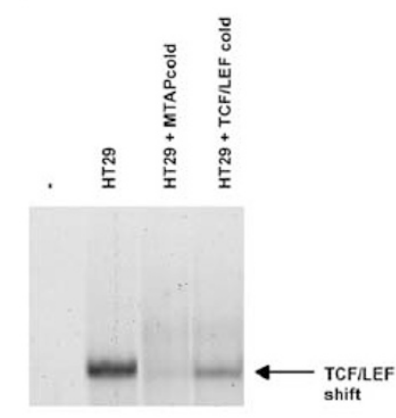

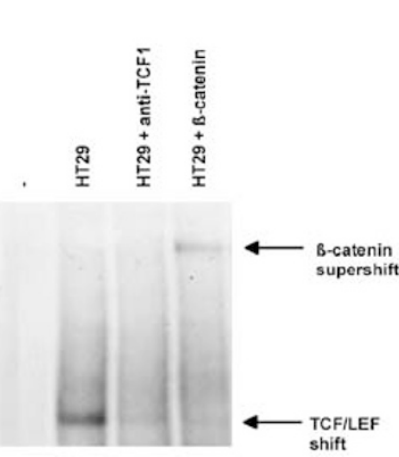

d

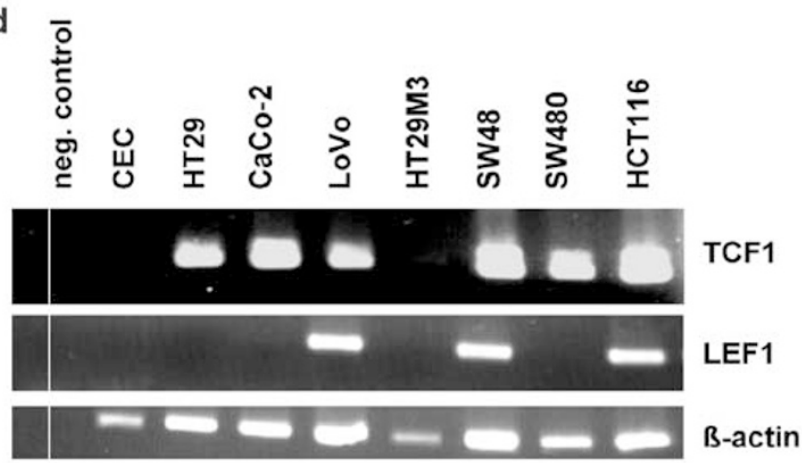

Figure 5 Regulation of MTAP expression in colon carcinoma cell lines and HT29M3 cells. (a) A reporter construct containing the luciferase gene under the control of the human MTAP promoter was transiently transfected into different colon carcinoma cell lines (HT29, HCT116, SW48, SW480, LoVo, Caco) and HT29M3 cells. The MTAP promoter showed strong activity in all colon carcinoma cell lines but only little activity in HT29M3. These findings are in accordance with the RNA expression levels. (b) Regulation of the MTAP promoter construct was analysed in HT29 cells. Cotransfection of TCF1, LEF1, TCF4 and $\beta$-catenin, revealed strong transactivation of the MTAP promoter by TCF1 and TCF1 plus $\beta$-catenin. (c) Gel shift analysis using the TCF1 binding site of the MTAP promoter showed a defined shift using HT29 nuclear extracts. Competition of this shift was achieved using the same unlabelled oligonucleotide (MTAPcold) and a TCF/LEF consensus site (TCF/LEFcold). Addition of an antibody against TCF1 led to suppression of the shift, while an antibody against $\beta$-catenin resulted in a supershift. (d) TCF1 and LEF1 expression was analysed in the colon carcinoma cell lines and CEC by RTPCR. $\beta$-actin PCR was performed to ensure quality of RNA.

In addition to its known role in polyamine metabolism, a recent study by Mowen et al revealed that MTAP expression has the potential to modify STAT1 activity. Reduced activity of MTAP in the cell leads to accumulation of MTA, which acts as an inhibitor of methyltransferases. Mowen et al determined the methylation of arginine 31 in STAT1 by protein arginine $\mathrm{N}$-methyltransferase 1 (PRMT1) as an important modification. Loss of this modification leads to enhanced binding of protein inhibitor of activated STAT (PIAS1) to STAT1 and therefore inhibition of STAT1 DNA binding activity. As STAT1 is essential for IFN signalling pathways, lack of MTAP expression is expected to cause reduced response of the cells to IFN treatment.

In accordance with this hypothesis, the differential expression of MTAP in the individual colon carcinoma cell lines correlated with the growth inhibitory effects of IFN-gamma. HT29M3 that served as a model for more differentiated colonic

Figure 6 Comparison of $\beta$-catenin and MTAP immunostaining in normal colonic epithelium (a) and colon carcinoma (b). (a) (I) There was a strong membranous staining of $\beta$-catenin detectable in the epithelial cells at the basement and cervix of colonic mucosal crypts $(\times 100)$. (II) At the mucosal surface the epithelial cells showed an increasing cytoplasmatic/nuclear staining of $\beta$-catenin $(\times 400)$. In contrast, CEC at the cryptal basement and cervix were immunohistochemical negative for MTAP (III, $\times 100)$ and showed a strong cytoplasmatic immunoreactivity at the cryptal surface (IV, $\times 400$ ). (b) (I) Colon carcinoma with focal cytoplasmatic and regional nuclear immunohistochemical staining of $\beta$-catenin $(\times 100)$. (II) Carcinoma segments with predominantly cytoplasmatic $\beta$-catenin staining $(\times 400)$ showed simultaneously a weak cytoplasmatic MTAP expression (III, $\times 400)$. In contrast to sections of colon carcinoma with strong nuclear immunostaining of $\beta$-catenin (IV, $\times 400$ ), a concurrent increasing cytoplasmatic staining of MTAP was detectable $(\mathrm{V}, \times 400)$. 
a

B - catenin
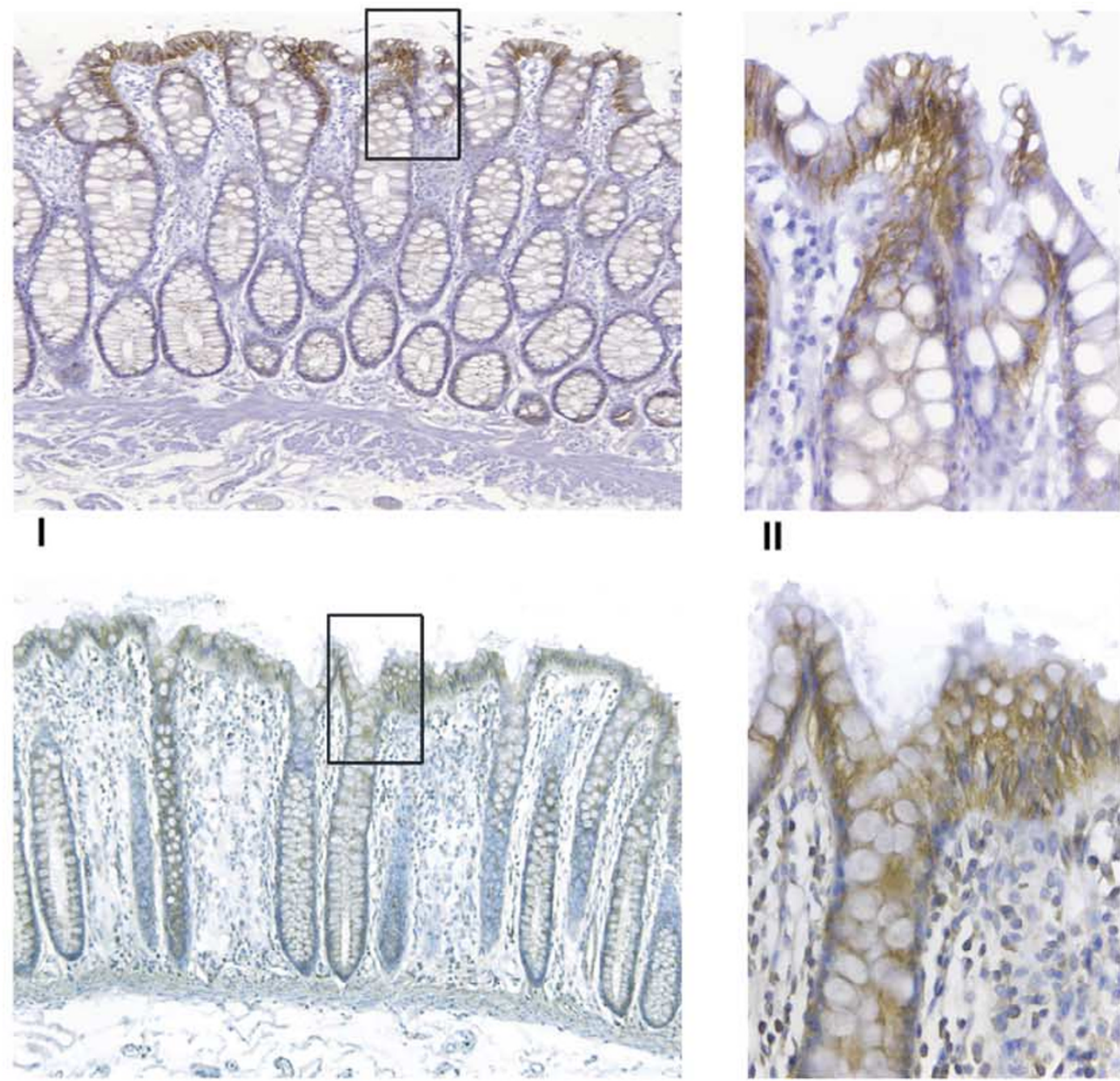

III

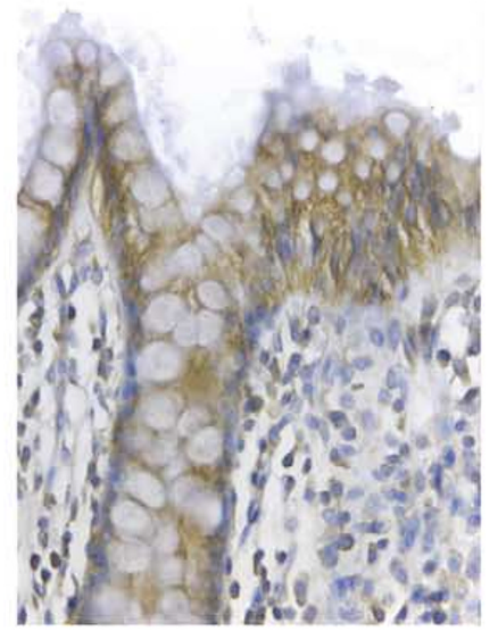

IV

b
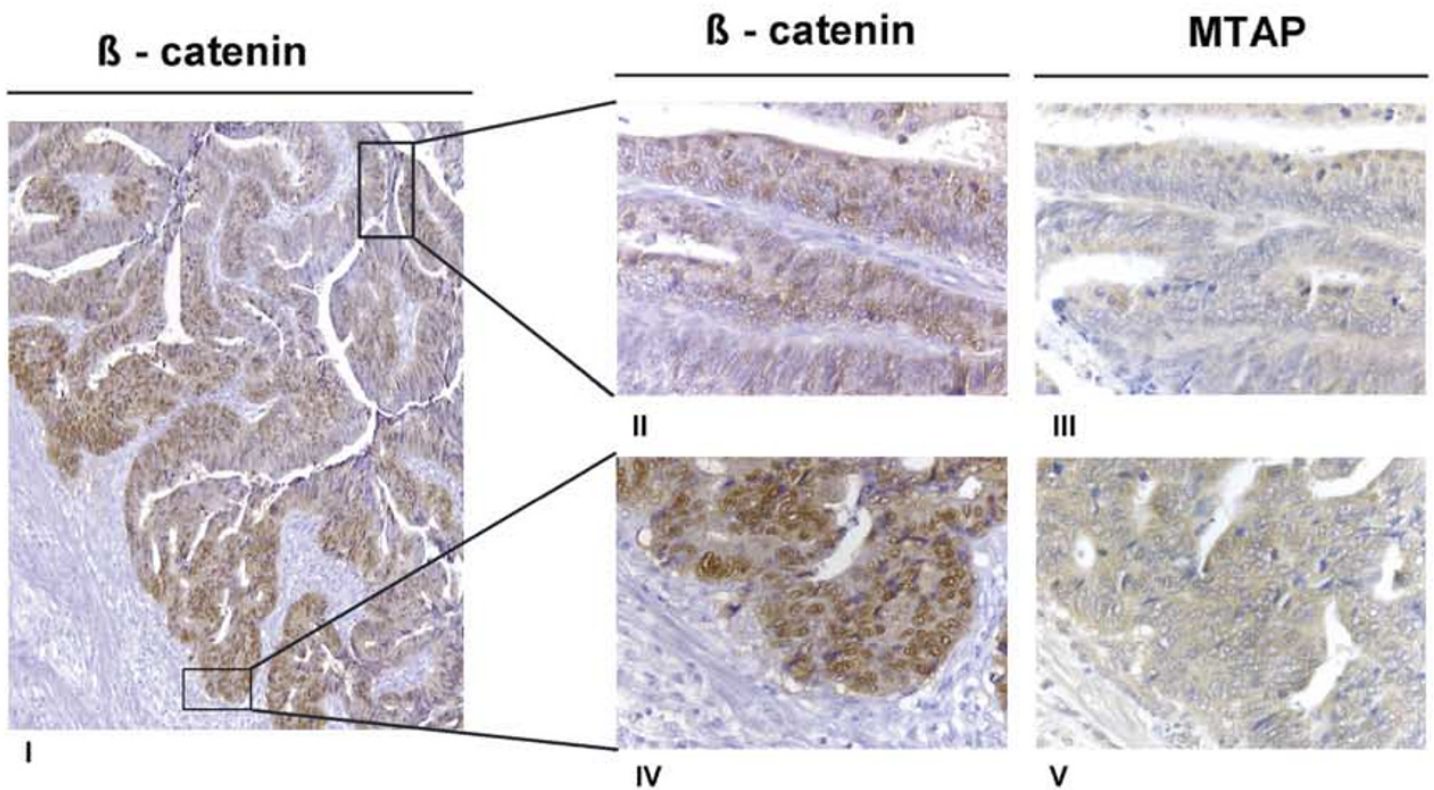
cells and SW480 revealed only weak MTAP expression and presented as almost completely resistant to the growth inhibitory effect of IFN-gamma. In contrast, HT29 and CaCo-2 (both strongly expressing MTAP) showed strong inhibition of growth in response to IFN treatment. The functional relevance of MTAP expression for the growth inhibitory effects of IFN on colon carcinoma cell lines was confirmed by expression of MTAP in HT29M3 that resulted in inhibition of cell proliferation by IFN-gamma.

Currently, we can only speculate on the physiological role of the reduced MTAP expression in

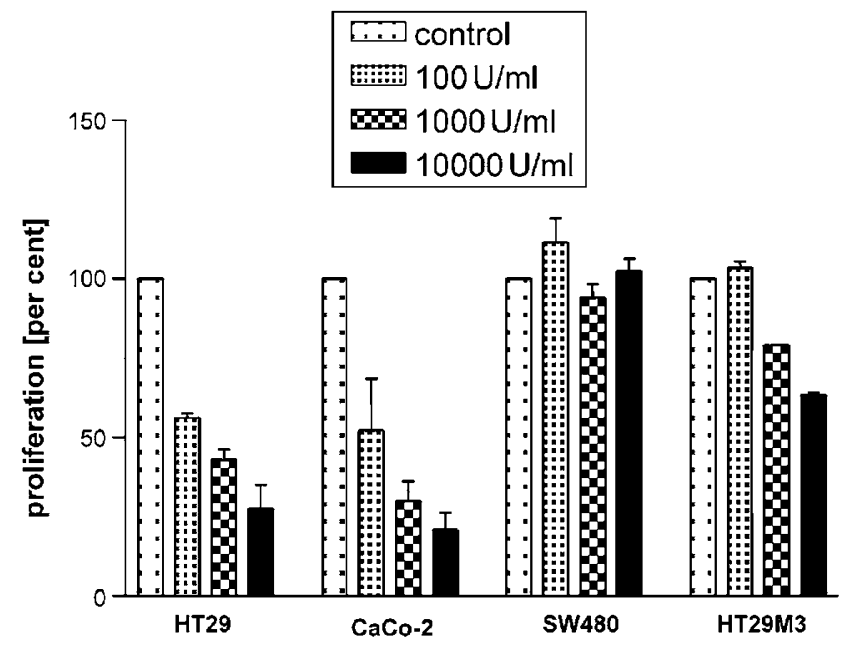

Figure 7 MTAP expression leads to higher sensitivity to IFN. Proliferation assays of the MTAP-expressing cell lines (HT29, CaCo) and the low MTAP-expressing cell lines (SW480, HT29M3) were performed under IFN treatment $(100,1000$ and $10000 \mathrm{U} / \mathrm{ml})$. Growth of the untreated cells (control) was set as 100 per cent.

Figure 8 Functional relevance of MTAP expression in colon carcinoma. (a) Real-time PCR and Western blot analysis of the HT29M3 cell clones stably transfected with an MTAP expression plasmid. All cell clones (MTAP1, 2 and 3) showed strong expression of MTAP whereas MTAP expression in the mocktransfected cell clones (mock1 and 2) remained low. (b) Proliferation assays of the MTAP-expressing cell clones (HT29M3 MTAP1, 2 and 3) and the low MTAP-expressing cell clones (HT29M3 mock1 and 2) were performed under IFN treatment (100, 1000 and $10000 \mathrm{U} / \mathrm{ml}$ ). Growth of the untreated cells (mock1,2) was set as 100 per cent. As demonstrated before, in HT29M3 cells no significant reduction of HT29M3 mock1 and 2 proliferation by IFN-gamma treatment was observed whereas growth of the MTAP stable transfected cell clones was significantly suppressed ( ${ }^{*} P<0.05 ;{ }^{*} P<0.01$; NS: not significant). (c) Invasion assays (Boyden Chamber) of the cell clones revealed a strong invasive potential of the two analysed MTAP-expressing HT29M3 cell clones, MTAP1 and MTAP2, comparable to the colon carcinoma cell line HT29. In contrast, HT29M3 cells or mock-transfected cell clones revealed equally low invasive activity. Significant differences in the invasive potential of the cell clones MTAP1 and MTAP2 to HT29M3 were revealed. Data are expressed as percentage of invasion with HT29M3 set as 100 per cent (NS: not significant; ${ }^{* * *} P<0.001$ ). The stained filters of the Boyden Chamber assay are shown in the lower part of the figure. normal colonic epithelium. It may protect CEC from immunological processes that occur permanently at the barrier between intestinal immune cells and bacteria also under physiological conditions. ${ }^{33}$ Moreover, under conditions of inflammation, the rapid wound healing including proliferation of CEC is essential to regain the intestinal homeostasis. Since IFN-gamma is highly expressed during
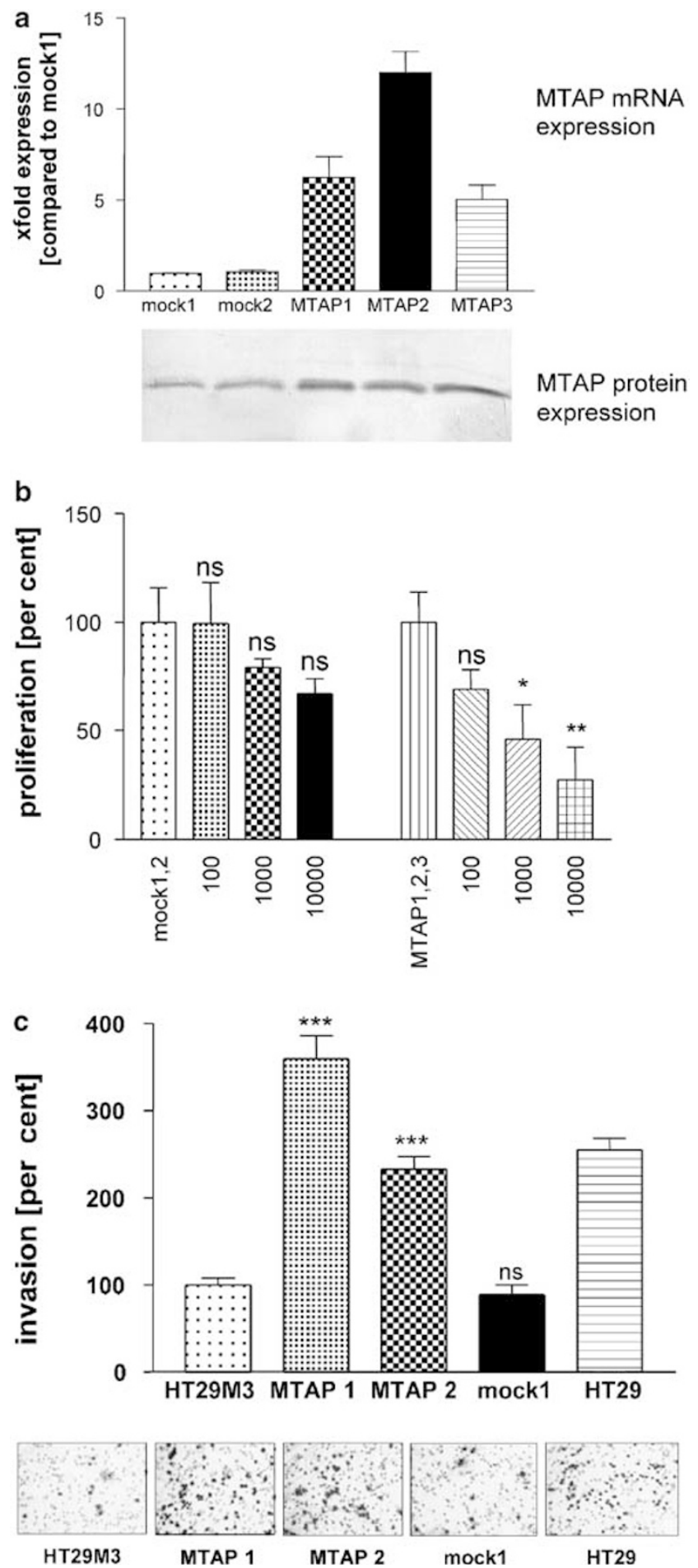
intestinal inflammation, ${ }^{34-36}$ the almost complete lack of MTAP expression may protect the cells from the growth inhibitory and proapoptotic effects of IFN-gamma also in vivo.

In contrast to normal colon epithelium, most of the colon carcinoma cell lines and all colon carcinoma analysed showed strong MTAP expression. As determined by immunohistochemistry, expression of MTAP was gradually increased during progression and dedifferentiation of the tumours. MTAP expression is also different to other kinds of tumours analysed previously like melanoma and mamma carcinoma. ${ }^{21,37}$ In these studies, MTAP was described as a tumour suppressor and loss of MTAP expression was associated with enhanced migration and invasion. Therefore, the role of MTAP in colon carcinoma was unclear. In our analysis, a role for MTAP in supporting cell migration and invasion of colon cells was shown. HT29M3 cell clones expressing MTAP after stable transfection with an MTAP expression plasmid revealed a strong induction of the invasive potential. Interestingly, in melanoma the effect of MTAP on the invasive potential was quite controversial. One potential explanation for this finding is that MTAP function differs comparing different cell types. Therefore, we see inhibition of invasion in a cell type derived from neural crest cells (melanoma) whereas in epithelial cells induction of migration is found. In colon cells downregulation of $\mathrm{TCF} / \beta$-catenin activity is associated with a more differentiated phenotype. ${ }^{38}$

Moreover, the differential expression of MTAP in colon carcinoma cell lines and the response to the growth inhibitory effects of IFN-gamma may have clinical implications. It has been shown previously that IFN-gamma sensitises human colon carcinoma cells to TRAIL-mediated apoptosis. ${ }^{12}$ The role of adjuvant treatment in the therapy of colon carcinoma is an area of intense investigation and there is controversy on the benefit of IFN-gamma treatment. ${ }^{39}$ However, several groups reported effectiveness of IFN-gamma against colon carcinoma cells in vitro and in vivo. ${ }^{40-43}$

It may be speculated that the correlation of IFN effects and MTAP expression found in vitro in colon carcinoma cells could also have impact on the therapeutically success in vivo and may eventually allow to predict the tumour response to IFN treatment. Clearly, this important question needs to be further addressed.

\section{Acknowledgements}

We are indebted to Sabine Troppmann, Manuela Gunkel and Gertrud Lallinger for excellent technical assistance and to Dr David Carson (University of California, USA) for supplying the anti-MTAP antibody. This work was supported by grants from the DFG and the Deutsche Krebshilfe to AB.

\section{References}

1 Olopade OI, Pomykala HM, Hagos F, et al. Construction of a 2.8-megabase yeast artificial chromosome contig and cloning of the human methylthioadenosine phosphorylase gene from the tumor suppressor region on 9p21. Proc Natl Acad Sci USA 1995;92:6489-6493.

2 Christopher SA, Diegelman P, Porter CW, et al. Methylthioadenosine phosphorylase, a gene frequently codeleted with p16(cdkN2a/ARF), acts as a tumor suppressor in a breast cancer cell line. Cancer Res 2002;62:6639-6644.

3 Garcia-Castellano JM, Villanueva A, Healey JH, et al. Methylthioadenosine phosphorylase gene deletions are common in osteosarcoma. Clin Cancer Res 2002;8: 782-787.

4 Wong YF, Chung TK, Cheung TH, et al. MTAP gene deletion in endometrial cancer. Gynecol Obstet Invest 1998;45:272-276.

5 Hori Y, Hori H, Yamada Y, et al. The methylthioadenosine phosphorylase gene is frequently co-deleted with the p16INK4a gene in acute type adult T-cell leukemia. Int J Cancer 1998;75:51-56.

6 Kamatani N, Carson DA. Abnormal regulation of methylthioadenosine and polyamine metabolism in methylthioadenosine phosphorylase-deficient human leukemic cell lines. Cancer Res 1980;40:4178-4182.

7 Mowen KA, Tang J, Zhu W, et al. Arginine methylation of STAT1 modulates IFNalpha/beta-induced transcription. Cell 2001;104:731-741.

8 Ramana CV, Gil MP, Schreiber RD, et al. Stat1dependent and -independent pathways in IFN-gamma-dependent signaling. Trends Immunol 2002;23: 96-101.

9 Schreiber S, Rosenstiel P, Hampe J, et al. Activation of signal transducer and activator of transcription (STAT) 1 in human chronic inflammatory bowel disease. Gut 2002;51:379-385.

10 McKay DM, Baird AW. Cytokine regulation of epithelial permeability and ion transport. Gut 1999;44: 283-289.

11 Sturgess RP, Hooper LB, Spencer J, et al. Effects of interferon-gamma and tumour necrosis factor-alpha on epithelial HLA class-II expression on jejunal mucosal biopsy specimens cultured in vitro. Scand J Gastroenterol 1992;27:907-911.

12 Langaas V, Shahzidi S, Johnsen JI, et al. Interferongamma modulates TRAIL-mediated apoptosis in human colon carcinoma cells. Anticancer Res 2001;21: 3733-3738.

13 Rogler G, Daig R, Aschenbrenner E, et al. Establishment of long-term primary cultures of human small and large intestinal epithelial cells. Lab Invest 1998;78: 889-890.

14 Grossmann J, Walther K, Artinger M, et al. Progress on isolation and short-term ex-vivo culture of highly purified non-apoptotic human intestinal epithelial cells (IEC). Eur J Cell Biol 2003;82:262-270.

15 Kitamura H, Cho M, Lee BH, et al. Alteration in mucin gene expression and biological properties of HT29 colon cancer cell subpopulations. Eur J Cancer 1996; 32A:1788-1796.

16 Lesuffleur T, Porchet N, Aubert JP, et al. Differential expression of the human mucin genes MUC1 to MUC5 in relation to growth and differentiation of different mucus-secreting HT-29 cell subpopulations. J Cell Sci 1993;106:771-783. 
17 Dahiya R, Lesuffleur T, Kwak KS, et al. Expression and characterization of mucins associated with the resistance to methotrexate of human colonic adenocarcinoma cell line HT29. Cancer Res 1992;52:4655-4662.

18 Lesuffleur T, Kornowski A, Augeron C, et al. Increased growth adaptability to 5 -fluorouracil and methotrexate of HT-29 sub-populations selected for their commitment to differentiation. Int J Cancer 1991;49:731-737.

19 Jacob K, Wach F, Holzapfel U, et al. In vitro modulation of human melanoma cell invasion and proliferation by all-trans-retinoic acid. Melanoma Res 1998;8:211-219.

20 Dietmaier W, Wallinger S, Bocker T, et al. Diagnostic microsatellite instability: definition and correlation with mismatch repair protein expression. Cancer Res 1997;57:4749-4756.

21 Behrmann I, Wallner S, Komyod W, et al. Characterization of methylthioadenosine phosphorylase (MTAP) expression in malignant melanoma. Am J Pathol 2003; 163:683-690.

22 Poser I, Golob M, Buettner R, et al. Upregulation of HMG1 leads to melanoma inhibitory activity expression in malignant melanoma cells and contributes to their malignancy phenotype. Mol Cell Biol 2003;23: 2991-2998.

23 Sobin LH, Wittekind CH, (eds). TNM Classification of Malignant Tumours. Springer-Verlag: Berlin, Heidelberg, New York, 2002; Wiley-Liss, Inc.: New York, 2002, sixth edn.

24 Ghiselli G, Coffee N, Munnery CE, et al. The cohesin SMC3 is a target the for beta-catenin/TCF4 transactivation pathway. J Biol Chem 2003;278:20259-20267.

25 Takahashi M, Fujita M, Furukawa Y, et al. Isolation of a novel human gene, APCDD1, as a direct target of the beta-Catenin/T-cell factor 4 complex with probable involvement in colorectal carcinogenesis. Cancer Res 2002;62:5651-5656.

26 Takahashi M, Tsunoda T, Seiki M, et al. Identification of membrane-type matrix metalloproteinase- 1 as a target of the beta-catenin/Tcf4 complex in human colorectal cancers. Oncogene 2002;21:5861-5867.

27 Conacci-Sorrell ME, Ben-Yedidia T, Shtutman M, et al. $\mathrm{Nr}$-CAM is a target gene of the beta-catenin/LEF-1 pathway in melanoma and colon cancer and its expression enhances motility and confers tumorigenesis. Genes Dev 2002;16:2058-2072.

28 Fujita M, Furukawa Y, Tsunoda T, et al. Up-regulation of the ectodermal-neural cortex 1 (ENC1) gene, a downstream target of the beta-catenin/T-cell factor complex, in colorectal carcinomas. Cancer Res 2001; 61:7722-7726.

29 Rockman SP, Currie SA, Ciavarella M, et al. Id2 is a target of the beta-catenin/T cell factor pathway in colon carcinoma. J Biol Chem 2001;276:45113-45119.

30 Brabletz T, Jung A, Dag S, et al. beta-Catenin regulates the expression of the matrix metalloproteinase-7 in human colorectal cancer. Am J Pathol 1999;155: 1033-1038.

31 Crawford HC, Fingleton BM, Rudolph-Owen LA, et al. The metalloproteinase matrilysin is a target of betacatenin transactivation in intestinal tumors. Oncogene 1999;18:2883-2891.

32 Tetsu O, McCormick F. Beta-catenin regulates expression of cyclin D1 in colon carcinoma cells. Nature 1999;398:422-426.

33 Carol M, Lambrechts A, Van Gossum A, et al. Spontaneous secretion of interferon gamma and interleukin 4 by human intraepithelial and lamina propria gut lymphocytes. Gut 1998;42:643-649.

34 Strober W, Velsall B, Fuss T, et al. Reciprocal IFNgamma and TGF-beta responses regulate the occurrence of mucosal inflammation. Immunol Today 1997; 18:61-64.

35 Parkos CA, Colgan SP, Madara JL. Interactions of neutrophils with epithelial cells: lessons from the intestine. J Am Soc Nephrol 1994;5:138-152.

36 Fiocchi C. Production of inflammatory cytokines in the intestinal lamina propria. Immunol Res 1991;10: 239-246.

37 Christopher SA, Diegelman P, Porter CW, et al. Methylthioadenosine phosphorylase, a gene frequently codeleted with p16(cdkN2a/ARF), acts as a tumor suppressor in a breast cancer cell line. Cancer Res 2002;62:6639-6644.

38 Mariadason JM, Bordonaro M, Aslam F, et al. Downregulation of beta-catenin TCF signaling is linked to colonic epithelial cell differentiation. Cancer Res 2001; 61:3465-3471.

39 Wiesenfeld M, O’Connell MJ, Wieand HS, et al. Controlled clinical trial of interferon-gamma as postoperative surgical adjuvant therapy for colon cancer. J Clin Oncol 1995;13:2324-2329.

40 Schwartzberg LS, Petak I, Stewart C, et al. Modulation of the Fas signaling pathway by IFN-gamma in therapy of colon cancer: phase I trial and correlative studies of IFN-gamma, 5-fluorouracil, and leucovorin. Clin Cancer Res 2002;8:2488-2498.

41 Kobayashi N, Kuramoto T, Chen S, et al. Therapeutic effect of intravenous interferon gene delivery with naked plasmid DNA in murine metastasis models. Mol Ther 2002;6:737-744.

42 Huang Y, Horvath CM, Waxman S. Regrowth of 5-fluorouracil-treated human colon cancer cells is prevented by the combination of interferon gamma, indomethacin, and phenylbutyrate. Cancer Res 2000; 60:3200-3206.

43 Sveinbjornsson B, Rushfeldt C, Seljelid R, et al. Inhibition of establishment and growth of mouse liver metastases after treatment with interferon gamma and beta-1,3-D-glucan. Hepatology 1998;27: 1241-1248. 